\title{
La cultura del miedo: el control de las emociones
}

En el eco de mi muerte aún hay miedo

¿Sabes tú del miedo? Sé del miedo cuando digo mi nombre.

Es el miedo, el miedo con sombrero negro escondiendo ratas en mi sangre, o el miedo con labios muertos bebiendo mis deseos.

Sí. En el eco de mis muertes aún hay miedo.

Alejandra Pizarnik (1958) Las aventuras perdidas

Quizás podríamos ubicar las reflexiones de este volumen dentro de lo que se denomina «giro afectivo», puesto que se presta atención a una emoción -el miedo- como una dimensión que vincula ámbitos aparentemente separados en la vida social. El «giro afectivo» recupera la sociabilidad de los afectos y los estudia como una suerte de economía de las emociones en donde aquéllos juegan un rol fundamental. Si bien las emociones no han sido desconocidas en la reflexión de filósofos y teóricos sociales aun desde la antigüedad clásica, en donde pasiones y humores motivaban una clasificación de los seres humanos, fue en la época moderna cuando los afectos recuperaron la atención como un modo de construcción y al mismo tiempo de condicionamiento de los sujetos. El descubrimiento de un espacio de la intimidad significó un primer llamado de atención, puesto que se vio la importancia de la actuación en el espacio público de emociones como el amor y el odio, del miedo y las pasiones en general.

Hubo pues un momento histórico -el Siglo de las Luces- en que las pasiones fueron vistas como peligrosas y negativas para la consecución de los objetivos civilizatorios. En el siglo XIX, momento de legalización de las ciencias del hombre, las emociones y los afectos permitieron una vívida clasificación de varones y mujeres. Allí se fabricó la condición femenina estableciendo una correspondencia negativa y una equiva- 
lencia entre mujer-emoción e imposibilidad del raciocinio. Mucho se ha analizado ya desde los feminismos el impacto del amor romántico, entre otros, como un dispositivo de control de los afectos en las mujeres, en particular en sus vínculos privados.

Más allá de los debates sobre los alcances de esta formación discursiva en la actualidad, lo cierto es que el estudio de los afectos aclara uno de los temas fundamentales en las reflexiones sobre la subjetividad: la imposibilidad de trazar un límite entre lo individual y lo social, entre lo personal y lo colectivo. Aunque desde diferentes perspectivas se había ya señalado las tensiones entre lo interno y lo externo en las actuaciones de los sujetos, el sinceramiento y la reflexión sistemática de estos temas se produce en contextos históricos que permiten comprobar las limitaciones de una reflexión en donde los afectos y las emociones son vistos como secundarios en los procesos de explicación de los fenómenos sociales.

Pero en el siglo XX hubo de producirse también una reflexión sobre el concepto de cultura que permitió la incorporación de los afectos en un entramado significativo y fructífero. Los procesos sociales se analizaron entonces no solo como un impulso de la razón, sino como una estructura de sentimiento en donde se remarcó la intersección de lo racional y lo pasional.

Esta idea de cultura señaló la importancia de esta dimensión en las transformaciones sociales acompañando el avance en el mundo contemporáneo de las tecnologías de la información y los medios audiovisuales. Queremos decir, para remitirnos al título, que los afectos se diferencian y se integran en la misma noción de cultura.

De esta forma, autorxs contemporáneas se han preocupado por reflexionar sobre las economías afectivas (Sara Amhed, Cecilia Macon, Adriana Cavarero, entre muchas otras) observando zonas diversas de afectos y socialidades: el estado, el cuerpo, los vínculos íntimos. Igualmente se ha tratado el amor, el odio, el dolor, la vergüenza, la repugnancia, el miedo.

Hay sin embargo un acuerdo teórico: emociones y afectos son construcciones sociales, marcadas históricamente y situadas en contextos sociales particulares.

Necesitábamos explicar este marco conceptual para luego detenernos en el tema específico de este número, que hemos denominado, tratando de señalar un sentido amplio y diversificado, «La cultura del miedo: el control de las emociones». 
Una lectura crítica fundamental que muestra actualmente la construcción del miedo es el documental del año 2002 realizado por Michel Moore titulado, «Bowling for Columbine». El director muestra a través de entrevistas y reportajes las causas de los asesinatos violentos que sucedieron en una escuela secundaria en Estados Unidos. Moore hace público lo que denomina «la cultura del miedo» desarrollada por los medios de comunicación norte americanos, al mismo tiempo que denuncia la incitación a la violencia, cuyo símbolo más reconocido es el Club del Rifle. Se explica por medio de imágenes algo que posteriormente será tratado por analistas sociales diversos: la economía del miedo como un método de control social.

Traemos este ejemplo pues nos ha parecido paradigmático respecto de la socialización del miedo como un estado de permanencia en los sujetos contemporáneos. Es necesario reflexionar entonces, acerca de los efectos sociales de estas políticas.

El miedo posee una ubicación particular en los discursos sociales del momento, podríamos delimitar un campo semiótico en el que aparecen términos relacionados tales como: temor, terror, pavor, pánico, espanto, horror, alarma, susto, sobresalto, recelo, aprensión, desconfianza, turbación, sorpresa, asombro, desasosiego. Cada una de estas palabras, se abre a series que remiten a su vez a otras constituyendo cadenas de significantes que se actualizan según episodios sociales, según los sujetos hablantes y sus pertenencias sectoriales. Si analizamos los términos primeros de este campo semántico vemos que todos ellos remiten a emociones con diversos grados de involucramiento de los sujetos y al mismo tiempo, con diversos grados de alteración. Es útil aquí señalar la diferencia entre miedo y angustia. Esta última carece de un objeto concreto, se presenta como una inquietud, un temor proyectivo sobre algo que el sujeto desconoce, mientras el miedo posee un carácter transitivo: tenemos miedo a la muerte, como en el poema de Pizarnik, tenemos miedo a la tortura como aquellxs que sufrieron encierro carcelario indiscriminado (y los que aun lo sufren).

Hay pues, una articulación semántica que no podemos dejar de mencionar. Los miedos se hallan en un constante juego con la violencia. Si las emociones se anclan en experiencias y prácticas sociales, el miedo en particular, se exacerba y se concreta en una figura liminar desde el punto de vista de una experiencia humana: el horror. El horror, como una intensificación del miedo parece circular en diferentes espacios geopolíticos. Cavarero (2009) habla de «horrorismo»: 
En el amplio repertorio de las violencias humanas, hay una particularmente atroz cuyos fenómenos podrían ser resumidos bajo la categoría de horrorismo. El recurso a un vocablo de nuevo cuño debe aquí reconducirse no sólo a la obvia semejanza con el término terrorismo sino, antes de nada, a la necesidad de subrayar aquel trato repugnante que, aunando muchas escenas de la violencia contemporánea, las engloba en la esfera del horror mejor que en la del terror. De modo que quizás bastaría nombrar el horror, sin ni siquiera tomarse la molestia del neologismo. El neologismo supone que algo sea nuevo, diferente, reciente. Pero, ¿̇qué hay, después de todo, de nuevo en la carnicería y en la tortura? ¿Qué hay de diferente en los cuerpos que se queman bajo las bombas incendiarias? ¿Qué hay de reciente en la habitual y vieja matanza de los inocentes? Al menos a primera vista y en ciertas circunstancias, una respuesta simple podría ser que es nueva la modalidad con la que esta matanza es ahora llevada a la práctica: un cuerpo que se hace explotar para lacerar a otros cuerpos. $\mathrm{Y}$ además, como cada vez sucede más a menudo, un cuerpo femenino, mejor dicho, a veces un cuerpo de una madre embarazada (p. 57)

Tal vez por eso hay teóricas (Ahmed, 2015) que relacionan miedos, violencias y cuerpos. Los miedos se prenden de los cuerpos, se estacionan, se materializan, adquieren formas y figuraciones diversas (miedo a la pobreza, el hambre, los extraños). Pero también circulan, por eso es que se podría tal vez señalar miedos epocales, que retuercen y crispan a lxs seres humanos. Nos arriesgamos a mencionar como un miedo epocal, el miedo al «otro», un miedo que se concreta en las diversas xenobobias que se han instalado en este mundo pequeño y globalizado.

Los artículos de este volumen realizan un minucioso recorrido de estas problemáticas, por ello iniciamos el número con un texto -traducido al español- de Fredric Jameson, quien reflexiona sobre la experiencia colectiva luego de los atentados del 11 de septiembre de 2001, poniendo el acento en el papel activo de los medios de comunicación, las lógicas políticas del capitalismo global y el avance del fundamentalismo religioso.

Siguiendo las categorías teóricas postuladas por Jameson, Ariel Gómez Ponce propone reflexionar sobre series televisivas actuales que escenifican los desbordes del miedo en el cuerpo social y señalan asimismo cambios sistémicos introducidos por la experiencia cultural de la posmodernidad en las culturas de Occidente. 
Partiendo del dato histórico de cómo se construyó en la Edad Media el miedo a las brujas creando una paranoia colectiva de delación, traiciones y oportunismos, canalizados por la Iglesia y por la Justicia, Silvia Barei analiza con ejemplos de la cultura latinoamericana actual, el modo en que se sostiene parte del entramado de nuestras sociedades violentas, aquello que se puede leer como tremendo o como desmesurado. Amenazas imaginarias que se vuelven reales y amenazas reales que se exacerban en el imaginario social.

El texto de Sebastián Moreno estudia cierto tipo de discursos de la derecha europea que han contribuido al surgimiento de un sentimiento general de alarma acerca de los migrantes como amenazas sociales, imponiendo una lógica de sentido relativamente estable y colectivo, caracterizada por emociones vinculadas con la desconfianza y con prácticas de discriminación hacia el otro cultural.

Juan Carlos Acerbi trabaja las transformaciones sociales del miedo y su conversión en terror, a partir del atentado a las Torres Gemelas. Dicho atentado instaló la premisa de que toda persona, independientemente de su nacionalidad o su religión, es sospechosa de ser una amenaza para la sociedad que habita. Por ello este artículo aborda la relación del miedo con la política y las consecuencias de la irrupción del terror como nueva variable que signa las subjetividades de las personas y las acciones de los gobiernos.

También Leopoldo Tilleria Aqueveque propone reflexionar sobre el fenómeno del miedo causado por el terrorismo contemporáneo más que como un efecto político o sociológico como una emoción estética que se produce en los sujetos una vez «representado» el incidente como escena trágica en términos de lo que Aristóteles en su Poética define como «miedo trágico». Se ejemplifica con cuatro acciones terroristas de este siglo: las Torres Gemelas, la toma del teatro Dubrovkade en Moscú, la ejecución de rehenes por el Estado Islámico y la masacre de Christchurchen en marzo de 2019.

Juan Camilo Ruiz Salazar reflexiona sobre «la construcción del miedo a la paz» desde las nociones de pasado, presente y futuro articulados en un territorio particular. Se trabaja específicamente con los discursos de los diálogos de paz entre el gobierno de Juan Manuel Santos y las FARC-EP, en Colombia.

El texto de Jessica Fajardo se enmarca teóricamente dentro de la filosofía política contemporánea y las teorías críticas de la violencia de Estado. Desde un acercamiento inicial al concepto de Estado de excep- 
ción se analizan los riesgos que corren los Estados y las sociedades democráticas de convertirse en Republicas policiales gobernadas por Oligarquías.

En perspectiva histórica, Soledad Monteagudo vuelve al proceso revolucionario iniciado en el Río de la Plata en 1810 sosteniendo que el miedo colectivo es uno de los elementos explicativos de la participación política de amplios sectores de la sociedad. Aunque este no fue el único factor, el análisis de los sucesos por los que atravesó la población de Buenos Aires desde fines del siglo XVIII, contribuyó a amplificar el sentimiento de ansiedad colectiva que se evidencia en las fuentes escritas y que explica en parte su accionar. A tal fin se analizan los discursos de la Iglesia y el modo en que esos miedos entraron en escena en el contexto revolucionario.

También en sede histórica Daniel Lvovich considera los sucesos de la Semana Trágica de 1919 en una perspectiva trasnacional, al analizar los modos en que la diplomacia y los servicios de inteligencia norteamericanos interpretaron los sucesos vinculándolos con un conjunto de eventos y procesos coetáneos. La Semana Trágica puede pensarse como un Gran Miedo de las élites argentinas y sudamericanas a una inminente revolución. El estudio trabaja con un conjunto de informes diplomáticos y de inteligencia de los Estados Unidos que se relevan en los National Archives and Record Administration (NARA) y en el Fondo Presidente Woodrow Wilson de la Biblioteca del Congreso de los Estados Unidos.

Como sea que se acentúe la gravedad de los sucesos pasados o contemporáneos, el presente volumen intenta promover diversas interpretaciones acerca de estos fenómenos que sobrevuelan insistentemente en las vidas de los sujetos, cualquiera sea su momento histórico o sus circunstancias personales. Esperamos que los lectores se sientan «afectados» y sean capaces de convocar a nuevas lecturas y nuevos lectores.

Adriana Boria y Silvia Barei

\section{Referencias bibliográficas}

Cavarero, A. (2009). Horrorismo. Nombrando la violencia contemporánea. México, México: Anthropos.

Ahmed, S. (2015). La politica cultural de las emociones. México, México: Programa Universitario de Estudios de Género de la UNAM. 